КОМАРОВСКИЙ Владимир Савельевич - доктор философских наук, профессор Института государственной службы и управления Российской академии народного хозяйства и государственной службы при Президенте РФ (119571, Россия, г. Москва, nр-кт Вернадского, 84, корп. 1; poiginalb@ yandex.ru)

\title{
ОБРАЗ ЖЕЛАЕМОГО БУДУЩЕГО РОССИИ: ПРОБЛЕМЫ ФОРМИРОВАНИЯ
}

\begin{abstract}
Аннотация. В статье анализируется образ желаемого будущего страны в сознании российской молодежи в его совпадении/расхождении с образом будущего, предлагаемого элитами. Автор выявляет составляющие образа будущего и особенности его формирования в современную эпоху, рассматривает возможные последствия влияния образа будущего на позиции и мировоззрение молодежи.

Ключевые слова: образ будущего, повестка дня, ценности, молодежь, элиты
\end{abstract}

$\mathrm{H}$ а рубеже веков мир вступил в эпоху невиданных ранее турбулентных трансформаций, последствия которых превосходят своим масштабом события Французской революции XVIII в. и Октября 1917 г. в России (3. Бжезинский). «Бытие на распутье» порождает неопределенность будущего, утрату понимания главных, ключевых направлений развития, препятствует ясному видению путей решения проблем, мешающих двигаться вперед. В полной мере сказанное относится и к России. Как отмечают специалисты, «важнейшим фактором жизни россиян в кризисные годы стала стремительно возросшая неопределенность, характеризующаяся неясностью настоящего и непредсказуемостью будущего, недостатком знаний о текущих событиях и условиях, в которых будет протекать деятельность» [Козырева, Смирнов 2019: 139].

В ближайшие годы проблема будущего станет еще более актуальной. Во-первых, в 2021 г. состоятся выборы в Государственную думу, а в 2024 г. выборы президента страны. Во-вторых, предстоит серьезная трансформация экономической модели страны в связи с исчерпанностью потенциала предшествующей, о чем говорят едва ли не все ведущие специалисты, а также свидетельствуют результаты хозяйственного развития последних лет. В-третьих, в жизнь вступает совершенно новое поколение, не знающее, что такое реальный социализм или «лихие 90-е», глубоко погруженное в Интернет и другие современные коммуникации. Отсутствие ясных и четких перспектив дезориентирует этих граждан, сужает временной диапазон планирования ими тех целей и перспектив, которых они хотели бы достигнуть, не позволяет предметно соотнести собственные цели и перспективы развития страны.

Одновременно условия перманентного транзита выдвигают новые, повышенные требования к личности, ее интеллекту, креативным способностям, умению мыслить и действовать вне шаблонных ситуаций, в условиях неопределенности и отсутствия четких правил игры.

Проект «желаемого будущего» формируется (предлагается, должен предлагаться) политической и интеллектуальной элитой. В то же время этот проект не может формироваться исключительно в политико-интеллектуальной среде. Он должен учитывать настроения и позиции широких масс населения, и прежде всего его наиболее продвинутых слоев молодежи - студентов, активной части старших школьников.

Контуры проекта будущего задаются и транслируются через СМИ, систему воспитания, другие средства правящей элитой (и отчасти другими политическими акторами), но не обязательно воспринимаются рядовыми гражданами, 
той или иной их частью. В связи с этим возникают проблемы сопоставления контуров проекта будущего, предлагаемого политическим руководством страны, элитами и политическими партиями, с одной стороны, и молодежи с другой; поиска ориентиров, целенаправленного формирования образа будущего, которые можно предъявить избирателям 2021 и 2024 гг.

Образ желаемого будущего - это не научный прогноз и не сценарный анализ состояния страны к тому или иному сроку. Он всегда так или иначе отражает условия наличного бытия тех субъектов, которые формируют (у которых формируется) этот образ.

В «Новой философской энциклопедии» образ определяется как результат реконструкции объекта в сознании человека, его внешних и внутренних свойств, связей, пространственно-временных отношений. Образ предстает в ощущениях, восприятиях, представлениях; является результатом взаимодействия субъекта и объекта «через активные преобразующие отношения субъекта к действительности». И, что для целей данной публикации особенно актуально, «главная его [образа] черта - репрезентация идеального, соединенная с нравственно-этическими оценочными суждениями» 1 .

Соответственно, желаемый образ страны - это видение будущего молодежью через призму своего «Я» - своих потребностей, интересов, ожиданий, идеалов, системы ценностей. Последнее не означает, что образ исключительно субъективен и не отражает реальных характеристик объекта. Это сочетание того и другого, причем в разных пропорциях у разных субъектов [Маленков 2015]. Уже в силу этого те наборы ключевых ассоциаций и характеристик, которые приписываются России молодежью и политической элитой, могут не совпадать. В добавление: образ будущего для молодежи и политической элиты (во всяком случае, политического руководства) имеет различное функциональное назначение. Хотя и у молодежи он имеет значение как ориентир для выстраивания жизненной стратегии, но в существенно меньшей степени, чем для политического руководства. Образ будущего молодежи - это в большей мере желаемое. В то же время образ будущего у политического руководства, на основе которого оно выстраивает стратегию развития страны, это в первую очередь возможное и необходимое, а потом - желаемое (быть конкурентоспособной в современном мире, стать $n$-ной экономикой в мировой табели о рангах и т.д.) [Образ будущего России... 2016].

Принципы и ценности в образе будущего в наиболее яркой форме представлены в программах политических партий, документах и программных заявлениях политического лидера страны: «реализовать в стране принцип правового (социального) государства», «утвердить народоправие» в том-то и том-то и т.д. Это образ отдаленного будущего. Наряду с образом отдаленного будущего, у него имеется еще одна ипостась - образ ближайшего будущего как перечень наиболее актуальных задач и проблем, подлежащих решению в определенные сроки (как правило, это время избирательного цикла), так называемая повестка дня.

Повестка дня общества, тех или иных его групп населения и повестка дня политического руководства в силу целого ряда причин могут существенно расходиться. Политическое руководство, политические элиты стараются, хотя бы декларативно, особенно перед началом нового политического цикла, уменьшить это расхождение повесток дня, заявляя о своей готовности решать проблемы, волнующие те или иные слои общества, общества в целом.

${ }^{1}$ Новая философская энциклопедия. М.: Мысль. 2010. Т. 3. С. 128. 
Образ страны принято анализировать в трех ракурсах:

1) общая оценка (позитивный образ - негативный);

2) в ракурсе отдельных проекций:

- пространственный образ (зависит от географических и природных факторов);

- символы страны (формальные - флаг, герб, гимн и т.д. и неформальные; исторически сложившиеся и сконструированные);

- личностная проекция (исторические личности, действующие деятели и т.д.);

- временная проекция (историческая память);

- цивилизационная проекция (выделение «нашей» и «чужой» культуры);

3) в ракурсе отдельных сфер общественной жизни (экономическая система и ее отдельные составляющие; социальная сфера - здравоохранение, качество жизни; политическая система - демократия, народовластие и т.д.).

Главными точками пересечения предлагаемого элитами проекта будущего и позиций рядовых граждан являются:

- содержание проекта, оптимальный маршрут движения вперед;

- ценностный статус генеральной идеи;

- горизонт планирования;

- способы и ресурсы достижения целей (не что делать, а как).

В полной мере о наличии проекта будущего можно говорить тогда, когда налицо ответы по всем названным позициям, что не исключает представления правящей элитой, другими политическими акторами тех или иных фрагментов проекта будущего и возможностей его соотнесения с представлениями о желаемом будущем молодежи.

Узловой момент - ценностный статус генеральной идеи. Для граждан ныне он обозначился, согласно данным многолетних исследований ученых Института социологии РАН, как смена приоритетов общественного развития - от обеспечения социально-экономической стабильности к широким преобразованиям в экономике, социальной и политической сфере, разрушению патерналистского консенсуса, новому видению роли государства в общественной и личиной жизни и утверждению социальной справедливости [Петухов В., Петухов Р. 2019].

Факторы, влияющие на формирование образа желаемого будущего России. Исходя из вышесказанного, в качестве ведущих, определяющих условий (факторов) формирования образа будущего можно выделить:

1) общемировые глобальные изменения, связанные с новым технологическим укладом, изменением «правил игры» на международной арене, места отдельных государств в мировом разделении труда и их роли как самостоятельных акторов, участвующих в формировании миропорядка;

2) исчерпанность потенциала роста у экономической модели, принятой на вооружение в России в начале нулевых годов, со всеми вытекающими негативными последствиями как для населения, так и для элит;

3) предстоящие в 2024 г. выборы президента России, когда, согласно Конституции, действующий президент должен покинуть свой пост;

4) особенности нового поколения, «поколения $Z$ », вступающего в политическую жизнь, будущих потенциальных избирателей кампаний 2021 и 2024 гг. (часть из них будут голосовать впервые).

В совокупности названные факторы создают ряд проблемных моментов формирования образа будущего. Главные из них:

1) в современных условиях «бытия на распутье», времени огромных изменений едва ли не во всех сферах жизнедеятельности, смысл и последствия кото- 
рых пока не ясны даже для продвинутых интеллектуалов, для политических элит, не говоря уже о рядовых гражданах, большая часть которых к тому же не может адаптироваться к этим переменам, будущее из сферы надежд и упований на лучшее нередко перемещается в область страха и опасений;

2) увеличивается дифференциал между опытом настоящего и ожиданиями будущего. Будущее предстает скорее как преодоление настоящего опыта, нежели его продолжение;

3) сужаются рамки рационального прогноза будущего и горизонт его планирования, равно как и горизонт ожиданий;

4) в общественном сознании обозначился поворот от будущего к прошлому (again policy), проявляющийся в стремлении политиков «вернуть» прежнее величие, гармонию и идентичность, обращая свой взор не в будущее, а в прошлое;

5) повсеместно наблюдаемый, хотя и с различной степенью интенсивности, огромный разрыв между элитой и остальными гражданами порождает смятение и недоверие этих граждан к предлагаемым элитой моделям будущего;

6) в эпоху глобализации постоянно увеличивается разрыв в уровне и качестве жизни между богатыми и бедными (относительно бедными) странами, преодолеть который не представляется возможным (или, как минимум, в обозримой перспективе) [Миланович 2017]. Это приводит к тому, что значительная часть населения последних (молодежи в особенности) перестает связывать свое будущее со страной проживания и стремится эмигрировать в более благополучные страны.

В разрыве между элитами и остальными гражданами ключевыми являются две проблемы: социальная несправедливость и так или иначе связанное с ней положение в экономике, рост которой способствует (хотя и не всегда, и не во всем) «сглаживанию» социальных дистанций между различными группами населения, а ее стагнация или кризис, - наоборот, увеличивает, поскольку исчезают возможности использования компенсаторных механизмов уменьшения неравенства. Россия после кризиса 2008 г. так и не восстановила темпы развития экономики. В последние годы перестала расти заработная плата, доходы населения. Согласно данным опроса населения, осуществленного в сентябре этого года в рамках заказа ФОМа 1 , $62 \%$ россиян считает, что экономика страны находится в кризисе. На исчерпанность возможностей существующей экономической модели и ее последствия многие специалисты указывали еще в начале нынешнего десятилетия.

Исчерпанность возможностей прежней модели экономической модели означает не только необходимость искать новую модель, но и неизбежную коррекцию господствующих социальных настроений, оценок и ожиданий, а также возможностей и стратегий элитных групп. Эта коррекция и ее социальные и политические последствия состоят в том, что на фоне низких и отрицательных темпов роста доходов стабильность в глазах общества воспринимается как стагнация. Пока рынок растет, в выигрыше, как правило, большинство. На стагнирующем рынке нечего делить, и «игра» сводится к борьбе за перераспределение убытков, и здесь проигравших всегда больше, чем победителей. Естественно, растет и число недовольных. В этой ситуации вопрос о справедливости распределения доходов выдвигается в центр повестки дня [Россия-2020... 2012: 135].

В сентябре нынешнего года (16.09.2019 г.) специалисты РАНХиГС опубликовали результаты мониторинга, согласно которым абсолютное большинство

\footnotetext{
${ }^{1}$ https://fom.ru/Economika/14257 (проверено 09.01.2020).
} 
населения России считает, что доходы в стране распределяются несправедливо, что становится одним из важных факторов, способствующих разложению общественных связей, нарушению трудовой этики, оправданию уклонения от налогов, росту агрессии в обществе. И это напрямую связано с темой будущего, неверия в собственный успех и успешность страны, возникновения желания ее поменять при первом удобном случае, восприятия страны как чужой («капитализм только для своих») [Ежемесячный мониторинг.. 2019]. Абсолютному большинству россиян существующий и постоянно растущий уровень неравенства представляется избыточным и несправедливым, закрывающим возможности вертикальной мобильности для граждан, пути инновационного развития и ведущим, в конечном счете, страну в тупик (страна с сомнительным будущим) [Комаровский 2017: 9].

Об опасности для страны совокупного негативного влияния стагнации экономики, неравенства и социальной несправедливости говорят и события последних месяцев в Москве.

Декан факультета мировой экономики и мировой политики НИУ ВШЭ Сергей Караганов, которого трудно заподозрить в предвзятости, так прокомментировал протесты лета 2019 г. в Москве, в которых наиболее активно приняла участие молодежь. Предостерегая молодежь от излишней «революционности», С. Караганов одновременно отметил, что вызвана эта негативная активность тем, что власть по-настоящему не занимается решением кардинальных проблем страны (прежде всего, стагнацией экономики), отсюда и отрыв от общества, закупоривание социальных лифтов и т.д. И общий вывод: «Если августовские протесты в Москве, при всей их карнавальности, не станут тем громом, после которого мужик, наконец, перекрестится, возьмется за дело, страну ждет убогое будущее... [перспектива] неизбежное скольжение вниз в условиях сокращающейся экономики и общественной базы» 1 .

В объемной монографии Владислава Иноземцева, который если и менее лоялен власти, тем не менее не относится к несистемной оппозиции, дается такая оценка перспектив России: страна исторически и органически несовместима с модернизацией, но при этом имеет достаточно прочную конструкцию, способную долгое время так или иначе противостоять вызовам современности, хотя, в конечном счете, рано или поздно ее ждет кризис и упадок [Иноземцев 2018].

Естественно, что подобного рода оценки в отношении будущего России распространены среди молодежи чаще, чем среди других групп населения. Прежде всего, в силу возрастных особенностей молодежи, которая видит зачастую один способ решения проблем - здесь и сейчас.

Представления молодежи о будущем во многом формируются в рамках «самокоммуникации» (Интернет) и влияния личного постмодернистского опыта сомнений/ревизии ценностей старших поколений и их подчиненности задачам текущего момента, ориентации на стиль жизни «цивилизации комфорта». Реальные возможности построения будущего для них менее значимы, чем привлекательные, завораживающие картинки бытия «за бугром». Немалую роль играет и неадекватная оценка многими молодыми людьми своих управленческих возможностей (полагают, что именно они знают, «как лучше»). Ряд исследователей (как в стране, так и за рубежом) отмечают, что совокупное влияние всех тех сдвигов, которые произошли в последние десятилетия в информационной сфере, экономике, международных отношениях и других сферах, привели к смене парадигмы образа и стиля жизни, где господствующим принципом становится персональный суверенитет, а вместе с ним и лично мотивированный

\footnotetext{
${ }^{1}$ Караганов С. Вспоминая революции. - Независимая газета. 21.08.2019.
} 
отказ от императива национально-территориальной идентификации и ориентации на иное видение будущего.

Сказанное выше относится главным образом к молодежи. Отсюда и несовпадение проектов будущего правящих элит и молодежи. И это может оказаться серьезной проблемой для власти на предстоящих выборах 2021 и 2024 гг.

Статья подготовлена при финансовой поддержке Российского фонда фундаментальных исследований, проект № 19-011-33019.

\section{Список литературы}

Ежемесячный мониторинг социально-экономического положения и самочувствия населения: 2015 - август 2019 г. (под ред. Т.М. Малевой). 2019. РАНХиГС при Президенте РФ. 53 с. Доступ: https://www.ranepa.ru/images/insap/insap/ Monitoring_16_09_2019.pdf (проверено 09.01.2020).

Иноземцев Владислав. 2018. Несовременная страна: Россия в мире ХХІ века. М.: Алиса Паблишер. 406 с.

Козырева П.М., Смирнов А.И. 2019. Доверие в нестабильном российском обществе. - Полис. Политические исследования. № 5. С. 134-147.

Комаровский В. 2017. Бедность и неравенство как вызовы национально-государственной идентичности и формированию гражданской нации в России. Власть. Т. 25. № 1. С. 5-11.

Маленков В.В. 2015. Образ России в восприятии жителей Тюмени. - Власть. T. 23. № 12. С. 129-134.

Миланович Б. 2017. Глобальное неравенство (пер. с англ. Д. Шестакова). М.: Институт Гайдара. 333 с.

Образ будущего России: желаемое, возможное, необходимое: материалы всероссийской научно-практической конференции. 2016. М.: МГПУ. 275 с.

Петухов В.В., Петухов Р.В. 2019. Запрос на перемены: причины актуализации, ключевые слагаемые и потенциальные носители. - Полис. Политические исследования. № 5. С. 119-133.

Россия-2020: Сценарии развития (под ред. М. Липман, Н. Петрова). 2012. М.: РОССПЭН. 588 с.

KOMAROVSKY Vladimir Savel'evich, Dr.Sci. (Philos.), Professor of the Russian Presidential Academy of National Economy and Public Administration (RANEPA) (bld. 1, 84 Vernadskogo Ave, Moscow, Russia, 119571; poiginalb@yandex.ru)

\section{IMAGE OF THE DESIRED FUTURE OF RUSSIA: PROBLEMS OF FORMATION}

Abstract. The article analyzes the vision for the image of desired future of the country by Russian youth, its coincidence and discrepancy in comparison with the image of the future proposed by the elites. The author reveals components of the image of the future and the features of formation in the modern era. The paper considers possible consequences of the influence of the image of the future on the position and worldview of youth.

Keywords: image of future, agenda, values, youth, elites 